\title{
Gomitras Vis - A - Vis Veterinary Officials in Jagatsingpur District of Coastal Odisha in Regards to Compatibility, Cohesiveness and Co-ordination
}

\author{
D.P. Swain, B.C. Das*, P. Swain, K. Chandraker and M.M. Mohapatra
}

Department of Veterinary and Animal Husbandry Extension, C.V.Sc and A.H., OUAT, Bhubaneswar, Odisha-751003, India

*Corresponding author

\begin{abstract}
A B S T R A C T
The study was conducted to know the compatibility, cohesiveness and Co-ordination among the Gomitras and concerned veterinary officials of Jagatsingpur districts so that, if any problem is there, can be sorted out to get a better AI performance. Altogether, 61

Keywords

Gomitra, Odisha,

Artificial

Insemination,

Veterinary officials

Article Info

Accepted:

16 August 2018

Available Online:

10 September 2018

Gomitras and 14 Veterinary Doctors working in all the 8 blocks of Jagatsinghpur district were selected as respondents for this study. The distribution of the respondents on the basis of their overall perception towards veterinarians and para-veterinarians revealed that the majority of the respondents $(52.45 \%)$ perceive at medium level that the veterinarians and others provide them assistance and support related to veterinary services. All the Gomitras in Jagatsinghpur district were well acquainted with both veterinary services and officials. All the Gomitras knew the local VO and visiting the Veterinary Dispensary regularly. On asking the frequency of visit to VD in a month, 78.68\% Gomitras answered between 1-10 times, while $19.68 \%$ said 10-20 times and 1.64\% Gomitras visited more than 20 times in a month. Veterinary officials are exerting substantial efforts in improving the skills of the Gomitras in Jagatsinghpur district. The study revealed that Gomitras are maintaining a healthy relationship with the local veterinary doctors. The performance of the Gomitras in Jagatsinghpur district is satisfactory as they have good knowledge on various activities related to livestock but still they need further improvement to enhance their knowledge through regular orientation.
\end{abstract}

\section{Introduction}

The livestock wealth of Odisha is impressive in numbers across all species, constituting a natural resource base with immense livelihood implications, even though productivity levels are very low. As per the 2012 livestock census, Odisha has a cattle population of 116.21 lakh, buffalo 7.26 lakh, goat 65.13 lakh, sheep 15.81, pig 2.8 lakh and poultry
198.9 lakh. Odisha contributed about 6.09 percent of cattle population in the country being $7^{\text {th }}$ in India. The total Exotic/CB cattle population in India is $21 \%$ where as in Odisha it is only $11.20 \%$ of the total cattle population of the state. As per the livestock census from 1992 to 2012 the population of CB/Exotic populations in India has increased from $7 \%$ to $21 \%$, but the progress of Odisha has not kept in pace with the country. Though Odisha 
stands $7^{\text {th }}$ in cattle population, its milk production is only $1.3 \%$ of the total milk production in the country which is $14^{\text {th }}$ in position. It is observed that though the per capita availability of milk has increased from $94 \mathrm{gms} /$ day in 2004-05 to $118 \mathrm{gms} /$ day in 2014-15, it is still far behind the all India per capita availability of milk $322 \mathrm{gms} /$ day in 2014-15.

Artificial insemination is an important component of dairy development and is being rendered through a network of 5,826 departmental AI centres in the State. The Frozen Semen Bank (FSB), located at Cuttack is the only semen producing station in the State, supplying semen to all the 30 districts. Presently 39 Jersey, 18 cross breed, 16 Redsindhi and 12 Haryana breeding bulls are maintained in this FSB. Hardly 10\% population is being served by Artificial Insemination whereas it is most effective and best way to upgrade the indigenous stock of bovine population for creating employment options through the enhancement of milk production and other related products(Singh and Sharma, 2014).Unavailability of trained man power, low awareness of the tribal people to breeding programmes, deficit in fodder production in the state, lack of village level veterinary institutions, etc., have prevented to achieve the target. Koloo et al., (2015) in their study on liberalisation of veterinary services in Kenya reported that private animal health assistants were perceived to provide better services than alternative providers because they are more accessible and offer services on credit. Breeding of animals is mainly through natural service with available bulls due to poor facility of A.I., Deficiency of quality feed and fodder, poor conception rate of A. I. (if available), little knowledge about vaccination of livestock and high morbidity and mortality in livestock have been identified as the major constraints in animal husbandry sector (Meena et al., 2007).
The GoO through NPCBB project has developed private AI workers and they are named as "Gomitra" in Odissa. As Gomitras are the private AI workers, reviewing their capabilities and efficiency can be helpful to uplift the milk production of the district as well as Odisha. They are trained by $\mathrm{AH}$ Department to provide AI services and other first aid in their locality. They used to provide AI, vaccination, VFA (veterinary first aid) at door step and also motivate farmers for genetic up-gradation of cattle and buffalo. They are being paid by GoO @ Rs.1000/month as fixed salary. Besides, they also earn incentive @ Rs.500/ calf born, up to maximum 10 calves in a month. The Gomitras have been placed in the service since 2000 by GoO. At present, 1466 Gomitras are working in the state of Odisha. Like Gomitras in Odisha, in Andhra Pradesh, Gopalmitras were performing as private AI workers (Reddy, 2014).

Jagatsinghpur district is very rich in livestock resources. There are number of institutions providing services to the livestock sector in the district. The district has one Veterinary Hospital, 12 numbers of Veterinary Dispensaries, one number of Disease Diagnostic Laboratory situated in the district headquarter Jagatsinghpur (for diagnosis of animal diseases), 92 Livestock Aid Centres, 156 AI Centres and 61 number of Gomitras which are catering to the services of livestock sector in the district which is shown in the table 1. Dairy dominates the livestock sector in the district and provides a majority of the income to the rural farmers. As per Livestock Census 2012, Jagatsinghpur district has a $1,19,199$ nos. of indigenous cattle, 1,77,677 nos. of crossbred cows and 11,292 nos. of buffaloes. If we compare the livestock census of the district between 2007 and 2012, there is decrease of $11.53 \%$ of Indigenous cattle in 2012 where as there is also an increase in $\mathrm{CB} /$ Exotic cattle in 2012 which gives evidence 
about the increase in AI activities in the district.

For a better outcome the relationship among the concerned officials and effectors are of utmost importance. Hence the study was conducted to know the Compatibility, Cohesiveness and Co-ordination among the Gomitras and concerned veterinary officials of Jagatsingpur districts so that accordingly if any problems are there can be sorted out to get a better AI performance.

\section{Materials and Methods}

Multistage purposive sampling followed for selecting respondents for the study. The district and block was selected purposively so that respondents are more in number to give a better picture of the study and they should be having a good experience in their field of work.

Jagatsinghpur is one of the densely populated districts of Odisha with livestock. This district has good track records in AI targets and milk production in the state. So the district was chosen as a model to study the activity of Gomitras and their constraints. All 8 blocks of Jagatsinghpur district were taken for data collection. Along with the Gomitras, their officials were also asked regarding their performances and their satisfaction level on Gomitra's activities. All the Gomitras and veterinary officials were questioned as respondent during the study. Two categories of the respondents were selected for the study. One was the Gomitras and second one was veterinary officials (officials of the FARD department). All the Gomitras working in the district were covered in the study. There were 61 Gomitras at the time of data collection. Thus, 61 Gomitras were included in the study. Besides, 14 officials of FARD department which included officials working in all the blocks of Jagatsinghpur District
(B.V.O/V.A.S/A.V.A.S) were also questioned in different aspects regarding the functioning of Gomitras. Thus, in total 75 respondents (61Gomitras and 14 officials) were selected from Jagatsinghpur for this study.

\section{Results and Discussion}

\section{Coordination of Gomitras with veterinary officials}

The Gomitras and veterinary department should work together to get better results in the field level. So, Gomitras were asked some questions regarding the working experience along with local veterinary officials (Table 1). All the Gomitras in Jagatsinghpur district were well acquainted with veterinary services and officials. All of them knew the local veterinary officials and visiting the Veterinary Dispensary (VD) regularly. On asking the frequency of visit to VD in a month, $78.68 \%$ Gomitras told between 1-10 times, while $19.68 \%$ visit $10-20$ times and remaining $1.64 \%$ Gomitras visited more than 20 times in a month, which suggests that all the Gomitras in Jagatsinghpur district are in well contact with the local VD for the purpose of receiving logistics, technical support, and other extension activities. Coordination is defined as the organization of the different elements of a complex body or activity so as to enable them to work together effectively. $96.72 \%$ Gomitras have treated or vaccinated animals along with the local veterinary officials, whereas $3.28 \%$ have never treated or vaccinated animals along with veterinarians. This may depend on the personal interest and availability of time of Gomitras and local veterinary doctor. In our country major contribution in AI network is from trained unskilled lay inseminations, without critical assessment of their skill and efficiency, which should be harnessed and evaluated regularly (Sharma et al., 2008). All the Gomitras admitted that Veterinary officer (VO) / livestock inspector (LI) ask them to do 
the follow up treatment. This shows the confidence of Veterinary officer (VO) /LI on the corresponding Gomitras that they can treat as per directions. $86.88 \%$ Gomitras has vaccinated1-5 times along with veterinarians and para-veterinarians whereas $13.12 \%$ Gomitras have vaccinated together for 5-10 times in a year.

Gomitras can clear their doubts during working together. They also can be demonstrated different precautions and methods to vaccinate or treat during these field visits. Satry and Raju (2004) in their study of Gopalmitras pointed that they were taught by giving emphasis on large ruminants (AI), to some extent on small ruminants, but much less on poultry, and negligible on pigs. Kaul and Prakash (1993) reported that 13.6 to $18.2 \%$ of wrong time inseminations (being performed in India which either causes man made infertility or reduces the production of animals). Thus close association and effective synergy between veterinary officials and
Gomitras may improve the technical expertise of Gomitras and in turn can reduce the incidences of faulty inseminations in cattle. All the Gomitras agreed that VO/LI discuss with them regarding the vaccination programmes in their area, VO guides them to perform work in a better way and also guides them to improve their A.I. skills. Thus this indicates that the efforts of veterinary officials in improving the skills of the Gomitras are substantial in Jagatsinghpur district. So if Gomitras in Jagatsinghpur Districts are having good skills then it may also be attributed to the veterinary department personnel and also Gomitras' own sincere interest to learn. Sastry and Raju (2005) reported that Gopalamitras actually treat the sick animals which is against provision of 'first aid', which according to the authors is over-reach by Gopalmitras, as they are indulging in use of antibiotics, use of analgesic and/or anti-allergy, doing injections, using uterine pessaries, surgical procedures and many more for which they are not qualified.

Fig.1 Distribution of the respondents on the basis of their overall perception towards veterinarians

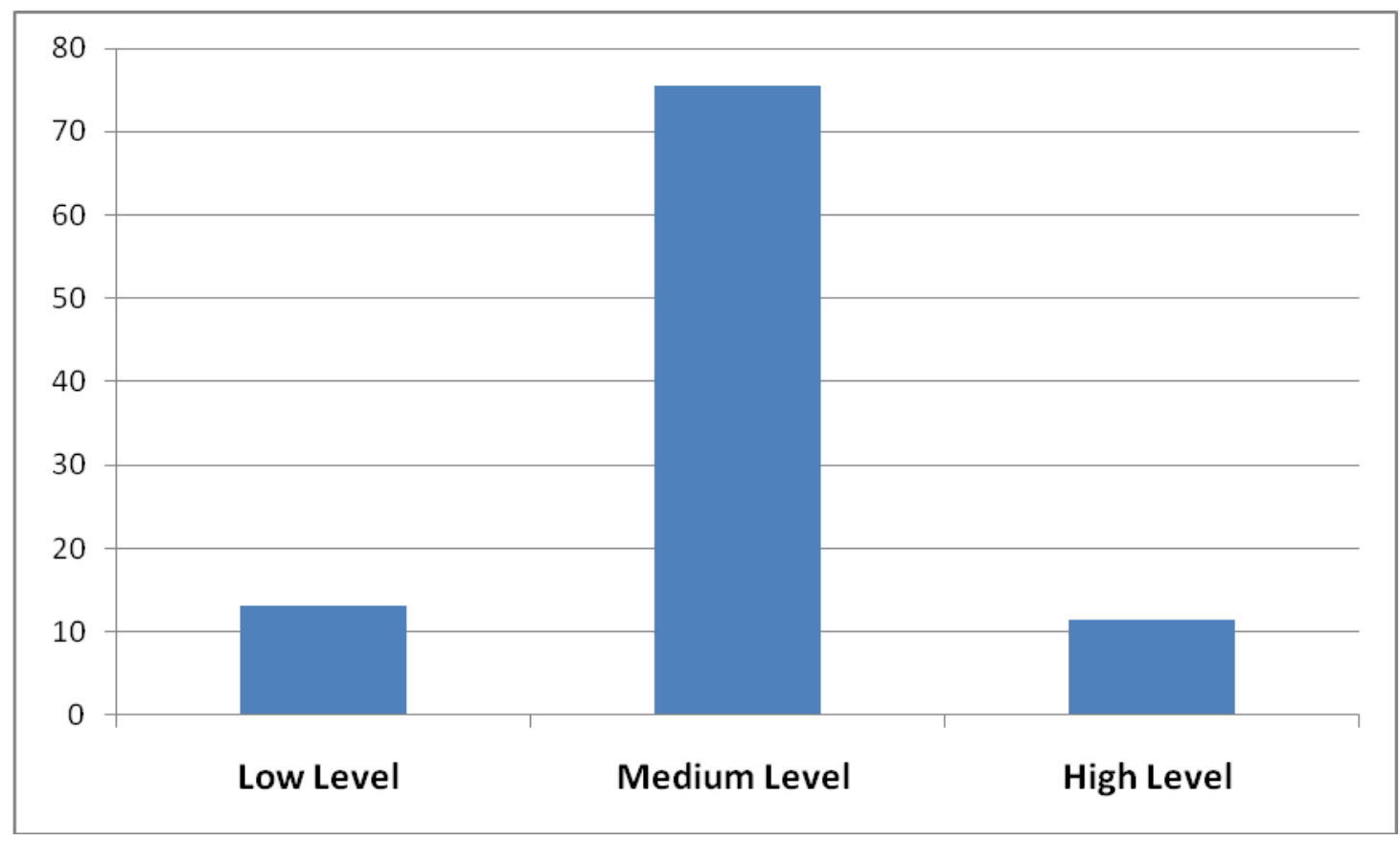




\begin{tabular}{|c|c|c|c|c|}
\hline $\begin{array}{l}\text { SI. } \\
\text { No. }\end{array}$ & & nents & $\begin{array}{l}\text { Total No. of } \\
\text { Respondent }\end{array}$ & $\begin{array}{l}\text { Percentage } \\
(\%)\end{array}$ \\
\hline \multirow[t]{3}{*}{1} & \multicolumn{4}{|c|}{ Do you know your local VO } \\
\hline & a) & Yes & 61 & 100.00 \\
\hline & b) & No & 0 & 0.00 \\
\hline \multirow[t]{3}{*}{2} & \multicolumn{4}{|c|}{ Are you visiting VD regularly } \\
\hline & a) & Yes & 61 & 100.00 \\
\hline & b) & No & 0 & 0.00 \\
\hline \multirow[t]{4}{*}{3} & \multicolumn{4}{|c|}{ How many times visiting VD in a month } \\
\hline & a) & $1-10$ & 48 & 78.68 \\
\hline & b) & $10-20$ & 12 & 19.68 \\
\hline & c) & More than 20 & 1 & 1.64 \\
\hline \multirow[t]{4}{*}{4} & \multicolumn{4}{|c|}{ For what purposes, you visit VO centre } \\
\hline & a) & For logistics & 29 & \\
\hline & b) & For Technical support & 58 & \\
\hline & & $\begin{array}{l}\text { Others (Extension services, Vaccination, Visit } \\
\text { IVU) }\end{array}$ & 60 & \\
\hline \multirow[t]{3}{*}{5} & \multicolumn{4}{|c|}{ Have you ever treated or vaccinated animals together with veterinary officials } \\
\hline & a) & Yes & 59 & 96.72 \\
\hline & b) & No & 2 & 3.28 \\
\hline \multirow[t]{4}{*}{6} & \multicolumn{4}{|c|}{ How many times in this year you vaccinated animals together } \\
\hline & a) & $1-5$ & 53 & 86.88 \\
\hline & b) & $5-10$ & 8 & 13.12 \\
\hline & c) & $>10$ & 0 & 0 \\
\hline \multirow[t]{3}{*}{7} & \multicolumn{4}{|c|}{ Does VO/LI ask you to do the follow up treatment } \\
\hline & a) & Yes & 61 & 100.00 \\
\hline & b) & No & 0 & 0.00 \\
\hline \multirow[t]{3}{*}{8} & \multicolumn{4}{|c|}{ Does VO/LI discuss with you regarding the vaccination programmes in the area } \\
\hline & a) & Yes & 61 & 100.00 \\
\hline & b) & No & 0 & 0.00 \\
\hline \multirow[t]{3}{*}{9} & \multicolumn{4}{|c|}{ Does VO guide you to do work in a better way? } \\
\hline & a) & Yes & 61 & 100.00 \\
\hline & & No & 0 & 0.00 \\
\hline \multirow[t]{4}{*}{10} & \multicolumn{4}{|c|}{ Does VO guide you to improve your A.I skill? } \\
\hline & a) & Yes & 61 & 100.00 \\
\hline & & No & 0 & 0.00 \\
\hline & To & & 61 & 100.00 \\
\hline
\end{tabular}

So this also points towards the regulations on the role and activity of Gomitras in field conditions. Kumar et al., (2012) reported that in Bihar, farmers were approaching the 
private practitioners (Gomitras or Gopalmitras) and other health centres for artificial insemination and maintenance of general health of their animals. They observed that, despite aggressive livestock development programme launched by state government, all the blocks are still to be covered by artificial insemination programme. They also reported that marginal and small farmers do not have easy access to public A. I. centres and veterinary health and hygiene facilities. This indicates that veterinary officials are very less to carry out all the requisite activities in the field levels. In this case Gomitras or private workers are capable to narrow down the lacunae and also nice coordination with veterinary officials will sharpen their capabilities to handle their duties.

Distribution of the respondents on the basis of their overall perception towards veterinarians

The distribution of the respondents on the basis of their overall perception towards veterinarians and para-veterinarians revealed that the majority of the respondents $(75.41 \%)$ perceive at medium level that the veterinarians and others provide them assistance and support related to veterinary services. Whereas $(11.47 \%)$ of the respondents perceive highly and $(13.12 \%)$ of the respondents perceive lowly that the veterinarians and others provide them assistance and support related to veterinary services (Fig. 1).

The efforts of veterinary officials are substantial in improving the AI, treatment, vaccination skills of the Gomitras and also the Gomitras are maintaining a good relationship with the local veterinary doctors by visiting the dispensary regularly either for the receipt of logistics like liquid nitrogen, semen straws, vaccines, medicines, etc., or for assisting the officer in MVU and camps.

\section{References}

Kaul V, and Prakash BS. 1993. Application of milk progesterone estimation for determining the incidence of false estrus detection and ovulation failure in zebu and cross bred cattle and Murrah buffaloes. Indian Journal of Animal Sciences, 64: 1054-57.

Koloo TO, Ilukor J, Mockshell J, Ilatsia E D and Birner R.2015 in their study on liberalisation of veterinary services in Kenya. Tropical Animal Health and Production, 47: 243-245.

Kumar A, Singh KM. and Singh RKP. 2012. Role of Livestock Sector in Sustainable Livelihood Security in Bihar: Status and Opportunities. Available at SSRN 2062823.

Meena HR, Ram H, Singh SK, Mahapatra RK, Sahoo A and Rasool TJ. 2007. Animal husbandry practices at high altitude (> 6000 feet) in Kumaon region of Uttarakhand, India. Livestock Research for Rural Development, 19(11): 7.

Sastry NSR and Raju SR. 2004. ParaVeterinary Training Programmes in Andhra Pradesh". Pro-Poor Livestock Policy Initiative of FAO, Capitalization of Livestock Program Experiences India of SDC and Government of Andhra Pradesh (GoAP) [www. fao. org/ag/againfo/projects/en/pplpi/researc h. html].

Sastry NSR and Raju SR. 2005. Animal Health Workers in Andhra Pradesh: Service Delivery, Supplies, Support and Supervision. Pro-Poor Livestock Policy Initiative, 1-6.

Sharma HC, Dhami AJ, Sharma SK, Sarvaiya NP and Kavani FS. 2008. Assessment of estrus detection and insemination efficiency of AI workers in buffaloes through plasma progesterone profile 
under field conditions, The Indian Journal of Animal Sciences, 78(7).

Singh A.K. and Sharma NK. 2014. Constraints and Strategies for Effective
Utilization of AI Services As Perceived By Rural Youth of Patna District. Indian Research Journal of Extension Education, 12(2): 59-61.

\section{How to cite this article:}

Swain, D.P., B.C. Das, P. Swain, K. Chandraker and Mohapatra, M.M. 2018. Gomitras Vis - A

- Vis Veterinary Officials in Jagatsingpur District of Coastal Odisha in Regards to Compatibility, Cohesiveness and Co-ordination. Int.J.Curr.Microbiol.App.Sci. 7(09): 23762382. doi: https://doi.org/10.20546/ijcmas.2018.709.295 